\title{
THE ROLE OF SUSTAINABLE TRANSPORTATION IN THE PUBLIC HEALTH IMPROVEMENT
}

\author{
Raed Nayif Alahmadi \\ Dr., Assistant Professor of Transportation Engineering,Albaha University, Civil Engineering Department \\ Albaha City, Kingdom of Saudi Arabia
}

\begin{abstract}
This paper introduces sustainable transportation and its role in public health improvement. It goes through the effect of Transportation policy and planning decisions in health. It discusses the Sustainable Transportation Area of impact in terms of Traffic Accidents, Pollution Emissions, Physical Activity and Fitness, Mental Health Impacts, Affordability, and Basic Mobility. This paper indicates that public transit improvements and more transit-oriented development can provide largely but often-overlooked health benefits. People who live or add communities with high-quality conveyance tend to drive significantly less and rely more on alternative modes (walking, cycling, and public transit) than they would in more automobile-oriented areas. This reduces traffic crashes and pollution emissions increase physical fitness and mental health, and provides access to medical care and healthy food.
\end{abstract}

\section{KEYWORDS}

Transportation, Health, Traffic, Sustainable

\section{INTRODUCTION}

Numerous researchers, institutes, and government organizations are working on reducing traffic congestion and building a sustainable transportation system all around the world. The common conclusion for this problem is that it is not feasible to continue to consume resources at current rates and the time is limited to take action. These conclusions cause the thought of sustainable development implementations on transportation systems. "Sustainable development" was defined by the United Nations' Report in 1987 as; "generating a development which meets the needs of the present without compromising the ability of future generations to fulfills their own needs." This definition is often restatement for systems of transportation as ensuring that future generations' need for mobility and transport will not be compromised. Researchers, governors, decision-makers, etc. are still working on building a sustainable world, and sustainable transportation systems, however, the results of these efforts do not indicate significant improvements. The concept of sustainable development is not straightforward since it has various indicators. For instance, transportation affects fuel (petroleum) reserves, global atmosphere, local air quality, sound pollution, level of mobility, congestion rate, and mortality rates (fatalities and crashes). Congestion and level of mobility are directly affected by the increase of VMT and the number of vehicles. Today in most urban areas, traffic congestion is one of the main concerns of residents. Even the local government agencies invest enormous amounts of money to expand roads and reduce congestion; however, the results of these investments do not indicate significant benefits since the existing roads cannot be expanded to the infinity. In addition, congestion is the main reason for low air quality in urban areas, due to vehicle emissions. Traffic crashes are another issue that should be included as a part of sustainable development. According to the World Health Organization (WHO), crashes are responsible for almost 1 million fatalities each year and nearly 70 million injuries (2001) (World Health Organization, 2004). Fortunately, per 100 million VMT mileage death rates are decreased from 2 to 1.25 in the last 10 years in the U.S. This decrease in crash rates can be explained by an increase in enforcement of traffic laws and new traffic regulations by the U.S. Government in last decade. Also, every crash costs a significant amount of money to society. For instance, a moderate injury crash costs $\$ 392,000$ and where fatality crash costs $\$ 4.2 \mathrm{M}$ in 2009 dollars (costs converted from the year 2000 to the year 2009 by consumer price index). A template may be a set of designs and page layout settings that determine the looks of a document. 


\section{SUSTAINABLE TRANSPORTATION}

Sustainable transport as a term came into use as a logical follow-on from sustainable development and is used to elucidate modes of transport, and systems of transport planning, which are consistent with wider concerns about sustainability. There are many definitions of sustainable transport, and of the related terms of sustainable transportation and sustainable mobility. One such definition, from the ECU Union Council of Ministers of Transport, defines sustainable transportation together that:

* Allows the essential access and development needs of individuals, companies, and society to be met safely and during a manner according to human and ecosystem health, and promotes equity within and between successive generations.

* Is affordable, operates fairly and efficiently, offers a choice of transport mode, and supports a competitive economy as balanced regional development.

* Limits emissions and waste within the planet's ability to soak up them uses renewable resources at or below their rates of generation and uses non-renewable resources at or below the rates of development of renewable substitutes while minimizing the impact on the utilization of land and therefore the generation of noise.

Sustainability can extend beyond just emissions, efficiency, and operating. A life-cycle assessment involves production, use, and post-use considerations. Cradle-to-cradle design is more important than attention to one factor like energy efficiency. Sustainable transport refers to the broad subject of transport that is sustainable within the sense of social, environmental, and climate impacts. Elements for evaluating sustainability contains the actual vehicles used for road, water, or air transport; the source of energy; and thus the infrastructure wont to accommodate the transport (roads, railways, airways, waterways, canals, and terminals). Transport operations and logistics as transit-oriented development also are involved in the evaluation. Transportation sustainability is essentially being measured by transportation effectiveness and efficiency because of the environmental and climate impacts of the system. Short-term activity often encourages incremental improvement in fuel efficiency and vehicle emissions controls while long-term goals include migrating transportation from fossil-based energy to other alternatives like renewable energy and the use of other renewable resources. The whole life cycle of transport systems is subject to sustainability measurement and optimization. Sustainable transport systems make a positive contribution to the social, environmental, and economic sustainability of the communities they serve. Transport systems exist to supply social and economic connections, and other people quickly take up the opportunities offered by increased mobility, with poor households benefiting greatly from low carbon transport options. The advantages of increased mobility got to be weighed against the environmental, social, and economic costs that transport systems pose.

Transportation may be a tricky thing to research within the context of sustainability. It consists of part of the built environment: the physical infrastructure of roads, runways, airports, bridges, and rail lines that makes it possible for us to get around. It also consists partially of individual choices: what mode we use to urge around (car, bus, bike, plane, etc.), what time of day we travel, what percentage people we travel with, etc. It is also made from institutions: federal and state agencies, oil companies, automobile manufacturers, and transit authorities, all of whom have their own goals and their own ways of shaping the choices we make. Most importantly, transportation is complicated because it is what is called derived demand. With the exception of joyriding or taking a walk or bicycle ride for exercise, very rarely are we traveling just for the sake of moving. We are usually going from Point A to Point B. What those points are home, work, school, shopping and where they are located downtown, in a shopping mall, near a freeway exit influence how fast we need to travel, how much we can spend, what mode we are likely to take, etc. The demand for transportation springs from other, non-transportation activities. To know transportation sustainability, we have to know the spatial relationship between where we are and where we would like to travel, and therefore the infrastructure and vehicles that can help get us there. How can we set about making transportation more sustainable? There are three main approaches: inventing new technologies, charging people the complete costs of travel, and planning better so we increase accessibility but not mobility. 


\section{TRANSPORTATION HEALTH IMPACTS}

The policy of transportation and planning decisions can affect health in various ways. How people travel affects physical and mental states, including cancer, disorder, vehicle crashes, and diabetes, four major causes of death. This section discusses the major categories of public health impacts that tend to be significantly affected by transport policies and planning decisions. Travel activity affects public health in several ways. Figure 1 indicates ways in which travel activity affects the ten leading causes of Potential Years of Life Lost (PYLL, which takes under consideration age of death and thus reflects the larger costs to society of risks to younger people). The contribution of pollution in some diseases is noticeable like cancer and congenital anomalies (birth defects) whereas sedentary living (inadequate physical activity) contributes to heart condition and strokes. Transport activity affects five of those health risks, including the three largest, which cause quite $60 \%$ of total potential years of life lost.

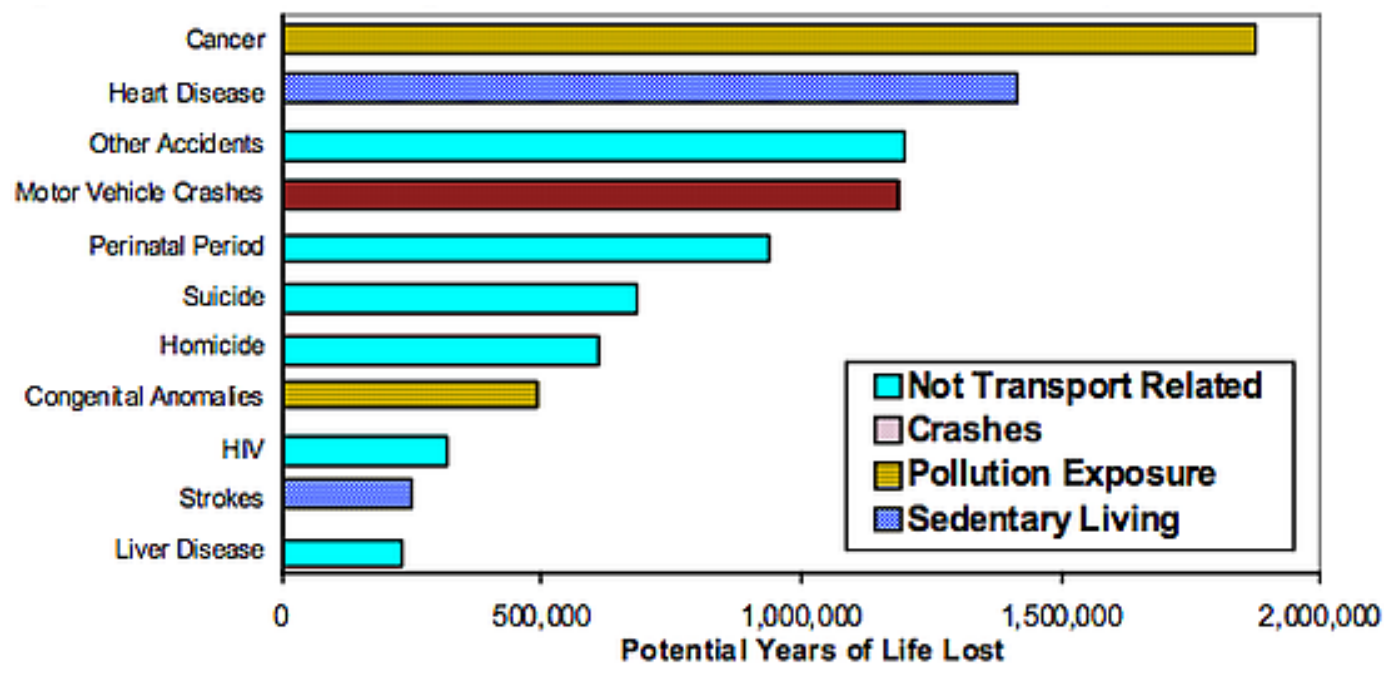

Figure 1. Ten Leading Causes of Potential Years of Life Lost (NCIPC 2009)

Of course, these relationships are complex. There are often several steps between a planning decision and its ultimate health impacts. Transportation activities are only a minor contributor to some of these risks. For example, motor vehicles are only one source of pollution, and pollution is only one contributor to cancer and congenital anomalies, while sedentary living increases some forms of cancer, which are not reflected in this figure.

\section{SUSTAINABLE TRANSPORTATION AREA OF IMPACT}

\subsection{Traffic Accidents}

Traffic crashes are a major cause of injuries and deaths (together called casualties), particularly for people aged 4-44 years. This risk can be viewed in different ways, which lead to different conclusions about this danger and the effectiveness of traffic safety strategies. The conventional paradigm assumes that motor vehicle travel is overall safe and that most crashes result from specific high-risk groups and behaviors, such as inexperienced and impaired driving, so safety programs should target these drivers and activities. From this perspective, it is inefficient and unfair to increase safety by reducing overall vehicle travel because this punishes all motorists for problems caused by an irresponsible minority.

Crashes can be measured in different ways, which result in different conclusions about the risk of different modes and activities. Distance-based units, such as fatalities per 100 million vehicle-miles, ignore the additional risk that results from increased vehicle mileage and the safety benefits of travel reductions. Conventional traffic safety analysis tends to measure crash rates per unit of travel (i.e., injuries and fatalities 
per million vehicle-miles or billion passenger-kilometers). Evaluated this way, US crash rates declined nearly $80 \%$ between 1965 and 2010, indicating that conventional safety programs were successful. However, per capita vehicle travel more than doubled during this period, which largely offset declining per-kilometer crash rates (Figure 2). The mileage-based fatality rate declined by more than two thirds during this period, which implies that existing safety programs were effective. However, this was offset by increased mileage. When measured per capita, as with other health risks, there was little improvement despite significant increases in use of safety devices (seatbelts, helmets, airbags, etc.), reductions in intoxicated driving, improved road and vehicle design, faster emergency response, and improved medical care. Considering these factors, much greater casualty reductions should have occurred. For example, seatbelt use grew from virtually zero in 1960 to about $75 \%$ in 2000 , which alone should have reduced traffic fatalities $33 \%$ (seat belt use reduces crash fatality rates about $45 \%$ ), yet, per capita traffic deaths declined just $25 \%$ during this period.

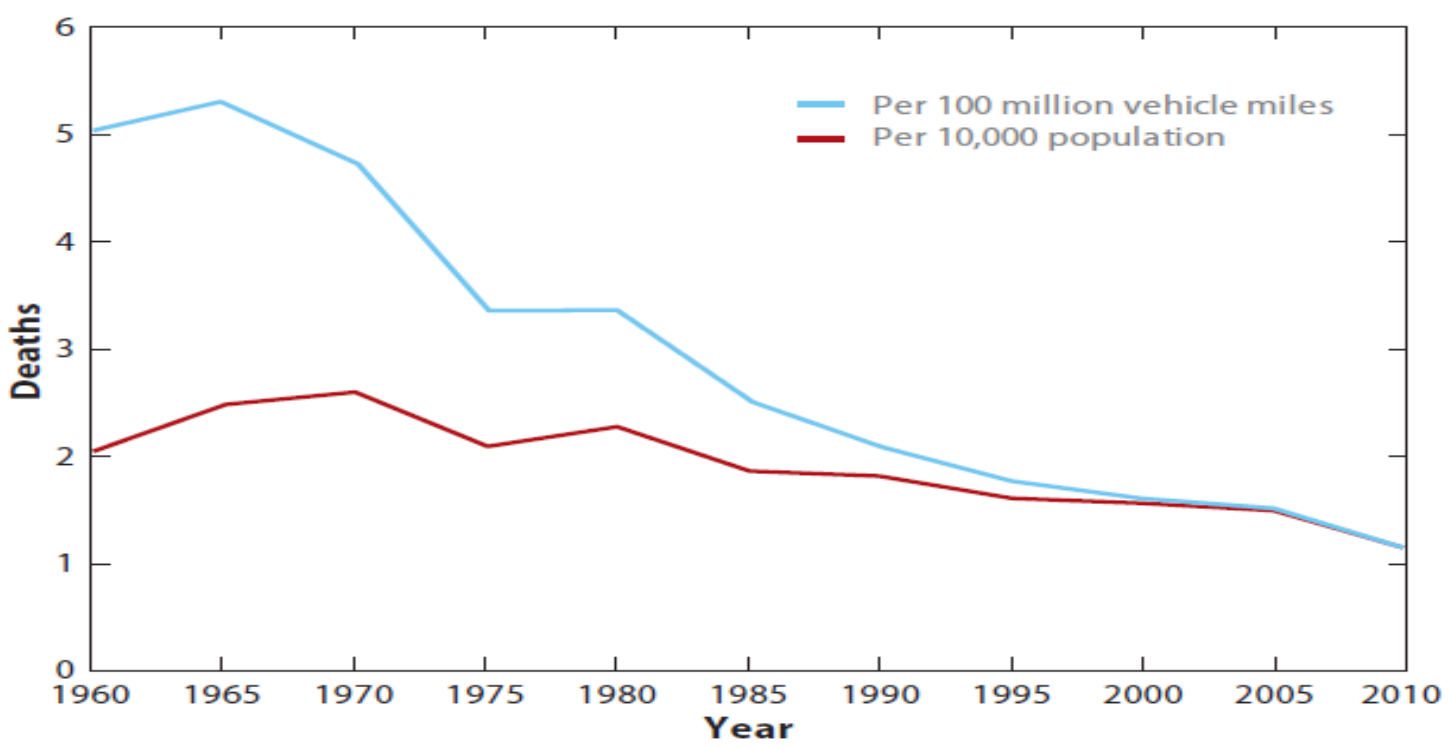

Figure 2. U.S. Traffic Fatalities between 1965 and 2010

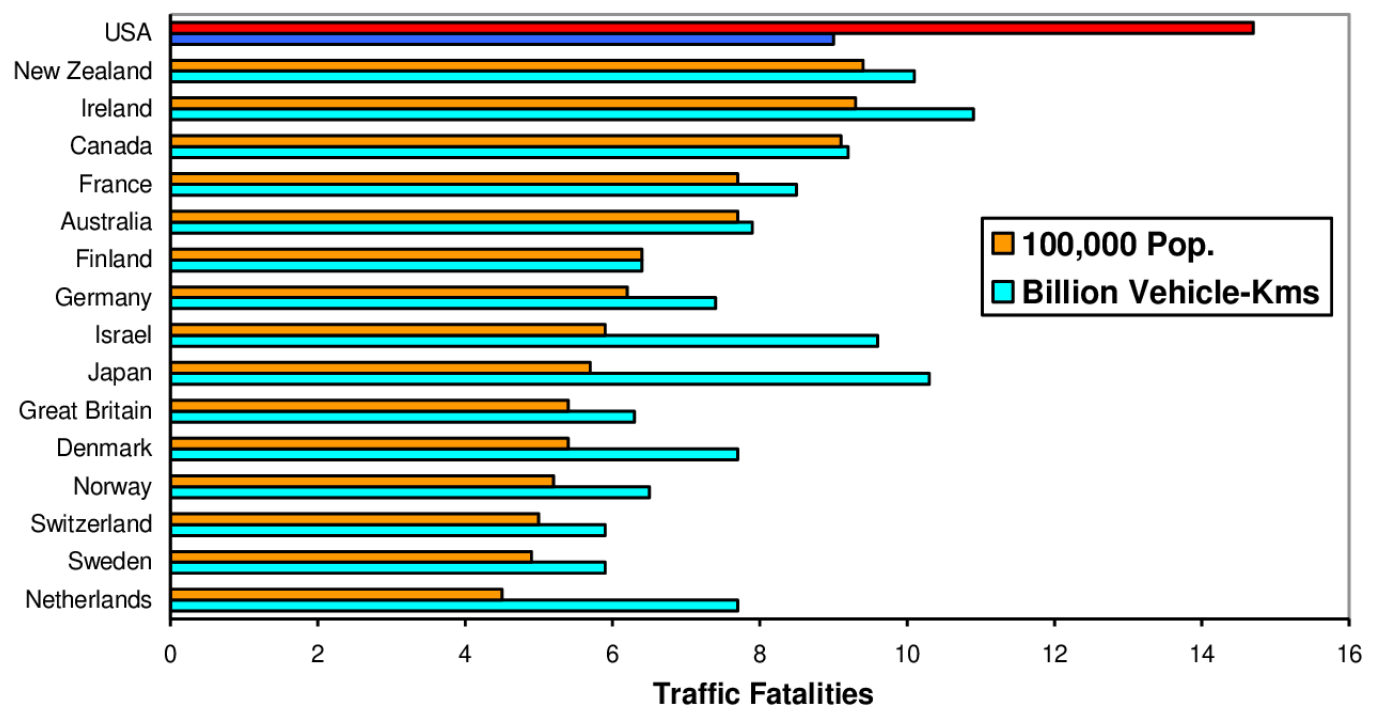

Figure 3. International Traffic Fatalities (Wikipedia 2009; based on WHO and OECD data) 
Traffic crashes still be one among the most important causes of deaths and disabilities for people aged 1-44 years. The U.S. has one of the lowest traffic fatality rates per vehicle-mile, it's one among the very high traffic fatality rates per capita, as illustrated in Figure 3, from this attitude, traffic risk continues to be a serious problem, despite high-quality highways and vehicles, and well-established safety programs. From this attitude, traffic crashes still be a serious health risk and new strategies could be justified to realize safety targets. Public transit may be a relatively safe mode, with only about one-twentieth the passenger death rate as automobile travel. Even considering risks to other road users, transit travel tends to possess a lower death rate per passenger-mile than automobile travel under equivalent conditions.

\subsection{Pollution Emissions}

Transport systems are major emitters of greenhouse gases, liable for $23 \%$ of world energy-related GHG emissions in 2004, with about three quarters coming from road vehicles. Currently, $95 \%$ of transport energy comes from petroleum. Consumption of energy within the manufacture also because of the use of vehicles and is materialized in transport infrastructure including bridges, railways, and roads.

The first historical attempt of evaluating the Life Cycle environmental impact of the vehicle is due to Theodore Von Karman. After decades during which all the analysis has been focused on emending the Von Karman model, Dewulf and Van Langenhove have introduced a model supported the second law of thermodynamics and exergy analysis. Chester and Orwath, have developed a similar model based on the first law that accounts for the necessary costs for the infrastructure.

Many factors affect vehicle pollutant human health impacts, including per capita vehicle mileage, vehicle emission rates, and exposure (the number of individuals located where emissions are concentrated). The number of premature deaths as traffic crashes is similar to the number of death due to motor vehicle pollution, although pollution victims tend to be older then cause smaller reductions in Potential Years of Life Lost than traffic crashes.

Public transit tends to supply less pollution per passenger-mile, particularly electric-powered and newer diesel vehicles, and as previously described, transit-oriented development tends to scale back per capita vehicle travel and associated emissions. Older diesel buses tend to possess high emission rates and bus transit tends to concentrate activity on the brink of roadways, so under some circumstances increased transit use may rise human exposure to some pollutants such as carbon monoxide and particulates. However, newer and alternative fuel buses produce far fewer emissions. Using fuels of less polluting ( like natural gas) increased from just $2.0 \%$ in 1992 to $30.4 \%$ by 2009 , and electric modes (electric trolleybuses and electric rail transit) increased from $29 \%$ to $34 \%$ of passenger-miles during an equivalent period.

The environmental impacts of transport are often reduced by reducing the load of vehicles, sustainable kinds of driving, reducing the friction of tires, encouraging electric and hybrid vehicles, improving the walking and cycling environment in cities, and by enhancing the role of conveyance, especially electric rail.

\subsection{Physical Activity and Fitness}

One of the major categories of health impacts concerns the effects that transport-planning decisions have on physical activity and fitness. Public health officials are increasingly concerned about declining fitness, excessive weight, and resulting increases in diseases like diabetes. They recommend that adults average a minimum of 150 weekly minutes (about 22 daily minutes) of moderate-intensity physical activity, and youngsters average about 3 times that quantity. A meta-analysis of 22 cohort studies concluded that, against a reported lack of physical activity, 2.5 hours of moderate activity per week were allegedly reduced by $19 \%$ in mortality, and 7 hours per week associated with a $24 \%$ decrease. In recent years, public health officials became increasingly alarmed at declining fitness and resulting increases in diseases related to sedentary lifestyles. Inadequate physical activity, and leading to excessive weight, contribute to heart and vascular diseases, strokes, diabetes, hypertensive diseases, osteoporosis, joint and back problems, colon and breast cancers, and depression. Even modest reductions in these illnesses can provide large savings and benefits. The World Health Organization (WHO 2000) states that regular physical activity can provide:

* $50 \%$ reduction in the risk of developing coronary heart disease (similar to not smoking).

* 50\% reduction in the risk of developing adult diabetes.

* $50 \%$ reduction in the risk of becoming obese.

* $30 \%$ reduction in the risk of developing hypertension. 
* 10/8-mmHg decline in blood pressure in people with hypertension (a similar effect to drugs).

* Reduced osteoporosis and falls in the elderly.

* Relief of symptoms of depression and anxiety.

\subsection{Mental Health Impacts}

Transport planning decisions also can affect the psychological states in various ways. Improving walking conditions, cycling and the transportation system tend to enhance the psychological state by increasing physical activity and supporting community cohesion, i.e. positive interactions between neighbors. Increased neighborhood walkability is associated with reduced symptoms of depression in older men, and reduced frequency of dementia in women and men. In a study of 299 US older adults (mean age 78 years) Erickson et al. found significantly higher rates of grey matter volume and cognitive ability in those that previously walked quite 72 blocks every week. High-quality public transit services can reduce commute stress compared with driving. Many commuters find a high-quality transportation system travel less stressful than driving. These psychological state benefits are difficult to quantify but potentially large.

\subsection{Affordability}

Affordability refers to reduced financial burdens, particularly for lower-income households. It generally means transportation expenditures are but $20 \%$ of household budgets, and transportation and housing expenditures total but $45 \%$ of household budgets. Public transportation and transit-oriented development can increase affordability by reducing the necessity to have and operate personal vehicles, by providing affordable mobility for non-drivers, and by reducing residential parking costs. This supports public health in several ways: it leaves households with extra money to get goods required for health, like adequate shelter, healthy food, and medical aid, and it reduces emotional stresses associated with poverty.

\subsection{Basic Mobility}

Basic mobility refers to peoples' ability to access services and activities considered essential, like healthcare services, basic shopping, banking, education and employment opportunities, and a specific amount of social and recreational activities. Public transportation and transit-oriented development provide basic mobility and accessibility, particularly for physically and economically disadvantaged people, like people with disabilities and lower-income seniors. This is substantial for public health and can leads to reduce healthcare costs. Inadequate mobility can cause patients to miss appointments, which exacerbates medical problems and wastes medical resources, or forces patients or health care agencies to buy more costly transport, such as taxis.

\section{CONCLUSION}

Transportation planning decisions can have significant health impacts by influencing traffic crash and pollution emission rates, physical activity, basic access, and psychological state. Conventional planning tends to consider some of these impacts, per-kilometer crash and pollution emission rates in particular, but generally ignore the health problems caused by degraded walking and cycling conditions and therefore the additional crashes and pollution emissions caused by increased vehicle mileage.

Public transportation can provide significant health benefits. People who live or work in communities with high-quality public transportation tend to own fewer vehicles, drive less, and use alternative modes more than they would in more automobile-oriented locations. This can provide large reductions in traffic crashes and pollution emissions, increases in fitness and psychological state, and improved access to healthy food, housing, and medical aid. These health benefits are so useful in magnitude compared with other planning objectives but are often overlooked or undervalued in conventional transport planning. 


\section{ACKNOWLEDGEMENT}

I am over helmed in all humbleness and gratefulness to acknowledge my depth to all those who have helped me to put these ideas for this paper, well above the level of simplicity and into something concrete. I would like to express my special thanks of gratitude to my wife for her stand with me to complete this paper. Any attempt at any level cannot be satisfactorily completed without the support and guidance of MY parents and friends.

\section{REFERENCES}

Berke EM, Gottlieb LM, Moudon AV, Larson EB. 2007. Protective association between neighborhood walkability and depression in older men. J. Am. Geriatr. Soc. 5

Chester et al., 2012 Infrastructure and Automobile Shifts: Positioning Transit to Reduce Life-cycle Environmental Impacts for Urban Sustainability Goals, Environmental Research Letters 8(1).

Chester M, and Horvath A, 2012, High-speed Rail with Emerging Automobiles and Aircraft Can Reduce Environmental Impacts in California's Future, Environmental Research Letters 7(3).

Chester M, and Horvath A, 2009, Environmental Assessment of Passenger Transportation Should Include Infrastructure and Supply Chains, Environmental Research Letters 4(2).

Intergovernmental Panel on Climate Change (2007). IPCC Fourth Assessment Report: Mitigation of Climate Change, chapter 5, Transport and its Infrastructure $(P D F)$. Intergovernmental Panel on Climate Change. Retrieved 2009-05-26.

Jeon, C M; Amekudzi (March 2005), Addressing Sustainability in Transportation Systems: Definitions, Indicators, and Metrics" (PDF), Journal of Infrastructure Systems, 11: 31-50, doi:10.1061/(ASCE)1076-0342(2005)11:1(31)

Larson EB,Wang L, Bowen JD, McCormick WC, Teri L, et al. 2006. Exercise is associated with reduced risk for incident dementia among persons 65 years of age and older. Ann. Intern. Med.

Litman T. 2007. Community cohesion as a transport planning objective. Pap. 07-0550. Presented at Annu.Meet. Transp. Res. Board, Washington, DC

Murray, et al. (1996). Global Burden of Disease and Injury. Center for Population and Development Studies, Harvard School of Public Health (www.hsph.harvard.edu/organizations/bdu).

Ont. Coll. Family Phys. 2005. The Health Impacts of Urban Sprawl. Volume Four: Social and Mental Health. An Information Series. Toronto: Ont. Coll. Family Phys. http://www.ocfp.on.ca/docs/committee-documents/urbansprawl-volume-4—social-and-mental-health.pdf?sfvrsn=5

Racioppi F, Dora C, Krech R, von Ehrenstein O. 2002. A Physically Active Life Through Everyday Transport: With a Special Focus on Children and Older People and Examples and Approaches from Europe, ed. A Davis. Rome: WHO, Eur. Reg. Off. http://www.euro.who.int/document/e75662.pdf

Schafer, A. (1998) The global demand for motorized mobility. Transportation Research A 32(6).

Subramanian R. 2012. Motor Vehicle Traffic Crashes as a Leading Cause of Death in the United States, 2008 and 2009. DOT HS 811 620. Washington, DC: Natl. Highw. Traffic Saf. Inst. (NHTSA). http://wwwnrd.nhtsa.dot.gov/Pubs/811620.pdf

Todd Litman (2009). Sustainable Transportation and TDM. Online TDM Encyclopedia. Victoria Transport Policy Institute. Retrieved 2009-04-07.

Todd Litman, 15 February 2012, Evaluating Public Transportation Health Benefits, Victoria Transport Policy Institute For The American Public Transportation Association

Tom Theis and Jonathan Tomkin, Editors, PDF generated: July 5, 2012, Rice University, Houston, Texas

Trancossi, M. (2014). What price of speed? A critical revision through constructal optimization of transport modes. International Journal of Energy and Environmental Engineering.

US Dep. Health Hum. Serv., Phys. Act. Guidel. Advis. Comm. 2008. Physical Activity Guidelines Advisory Committee Report, 2008. Atlanta: USDHHS. http://www.health.gov/paguidelines/ report/pdf/CommitteeReport.pdf

US Dep. Transp. Fed. Highw. Adm. (FHA). 2010. Transportation Planner's Safety Desk Reference. FHWA-HEP-10001. Washington, DC: USDOT, FHWA. http://tsp.trb.org/assets/ FR1_SafetyDeskReference_FINAL.pdf

U.S. Department of Transportation's Research and Innovative Technology Administration, May 2010, Helping to Build a Safe and Sustainable Transportation Infrastructure (PDF), U.S.A.

Woodcock J, Franco OH, Orsini N, Roberts I. 2010. Non-vigorous physical activity and all-cause mortality: systematic review and meta-analysis of cohort studies. Int. J. Epidemiol. 